\title{
PATRICK CHAMOISEAU, Frères migrants
}

\section{Roberto Ferraroni}

\section{(C) OpenEdition}

\section{Journals}

\section{Edizione digitale}

URL: https://journals.openedition.org/studifrancesi/14223

DOI: 10.4000/studifrancesi. 14223

ISSN: 2421-5856

\section{Editore}

Rosenberg \& Sellier

\section{Edizione cartacea}

Data di pubblicazione: 1 août 2018

Paginazione: 377

ISSN: 0039-2944

\section{Notizia bibliografica digitale}

Roberto Ferraroni, «PATRICK CHAMOISEAU, Frères migrants», Studi Francesi [Online], 185 (LXII | II) | 2018,

online dal 01 août 2018, consultato il 15 novembre 2021. URL: http://journals.openedition.org/ studifrancesi/14223 ; DOI: https://doi.org/10.4000/studifrancesi.14223

Questo documento è stato generato automaticamente il 15 novembre 2021.

\section{(c) (i) (9)}

Studi Francesi è distribuita con Licenza Creative Commons Attribuzione - Non commerciale - Non opere derivate 4.0 Internazionale. 


\title{
PATRICK CHAMOISEAU, Frères migrants
}

\author{
Roberto Ferraroni
}

\section{NOTIZIA}

PATRICK CHAMOISEAU, Frères migrants, Paris, Seuil, 2017, 137 pp.

1 Il saggio che ci propone Patrick Chamoiseau, prolifico scrittore martinicano contemporaneo, tocca un argomento estremamente attuale, quello dei flussi migratori di persone che si vedono costrette ad abbandonare la loro terra d'origine in cerca di migliori condizioni di vita, di una possibilità di riscatto o di un'esistenza quantomeno dignitosa.

2 Leggendo questa breve composizione si ha come l'impressione che l'autore l'abbia scritta di getto, in modo del tutto naturale, senza fermarsi a cercare parole o contenuti da inserire, ma lasciando uscire liberamente i pensieri e le emozioni che gli vengono dal profondo del cuore. La fluidità della sua scrittura in quest'opera dimostra quanto sentisse il bisogno di esprimere, quasi di urlare poeticamente, il suo malessere interiore. Un malessere provocato da una società in cui non si riconosce più, che sembra aver dimenticato il proprio passato, che soprattutto sembra aver scordato il concetto di umanità. L'intero testo è un attacco diretto ai paesi economicamente forti, sferrato con forza ma senza violenza.

Chamoiseau rimprovera a queste nazioni di non saper rileggere e riconsiderare il proprio passato storico: come l'Italia, che fino a un secolo fa era una nazione di migranti diretti verso l'America in cerca di fortuna; o come la Francia che non ricorda di essere stata una nazione di viaggiatori che hanno raggiunto terre molto distanti dalla madrepatria per poterle colonizzare. Oggi che la loro economia è stabile questi paesi puntano solo a renderla più forte, ad arricchirsi, e girano lo sguardo di fronte a coloro che chiedono aiuto, dimostrando così di non riconoscere i valori dell'accoglienza, dell'asilo, carità e condivisione. Questa è una visione decisamente allarmante e da qui nasce l'angoscia a cui Chamoiseau dà libero sfogo nelle righe del saggio, sostenendo l'idea che ogni paese è "tutti i paesi", ogni uomo è "tutti gli uomini", che non ci 
dovrebbe essere distinzione tra "noi" e "loro". Il concetto stesso di "altro" è in un certo senso errato: l'umanità è un'unica entità, a prescindere dai singoli paesi in cui si nasce.

Tuttavia l'autore non vuole dare una visione totalmente negativa e sottolinea come si inizi ad avere l'impressione che qualcosa stia cambiando, che le persone stiano riscoprendo l'empatia e la compassione per chi si trova a vivere in condizioni di estremo disagio. Questa inversione di tendenza viene messa in stretta relazione con quella che è diventata l'immagine-simbolo della "piaga" del nuovo millennio: il piccolo Aylan che giace su una spiaggia, senza vita. Il bimbo stava scappando con la famiglia dalla Siria, cercando di raggiungere le isole greche a bordo di un piccolo gommone che si è rovesciato pochi minuti dopo la partenza. Il piccolo purtroppo è annegato durante la "traversata della speranza", e la foto del suo corpicino inerme, vestito solo di una maglietta rossa e un paio di jeans, è diventato l'emblema di ciò che non può, e non deve, essere più accettato. Era necessario arrivare a tanto per risvegliare le coscienze? Purtroppo è ciò che è successo, ma è importante che di fronte a quella foto tante persone si siano indignate e abbiano iniziato a far sentire la propria voce di protesta.

5 Un valore aggiunto lo ha sicuramente la conclusione di questo saggio che termina con una vera e propria "Déclaration des poètes", divisa in 16 articoli, nella quale si dichiara con forza che i poeti appoggiano e sostengono un'umanità che sia unica e unita, in cui non c'è spazio per odi, rancori, discriminazioni di alcun tipo, dove ci si aiuta sempre, dove nessuno viene abbandonato o lasciato indietro, dove il dolore di qualcuno è il dolore di tutti, la felicità di qualcuno è la felicità di tutti. L'ultimo articolo è rivolto direttamente ai migranti a cui i poeti dichiarano che «le vouloir commun contre les forces brutes se nourrira des infimes impulsions... Que le combat de chacun est le combat de tous» (p. 136), e che loro, i poeti, sono dalla parte di chi deve superare terribili prove per poter sperare in una vita migliore. 